\title{
Transient Elastography for Predicting Liver-Related Events in Cirrhotic HIV-Infected Patients
}

\section{Montes $\mathrm{ML}^{1 *}$, Berenguer $\mathrm{J}^{2}$, Miró $\mathrm{JM}^{3}$, Quereda $\mathrm{C}^{4}$, Hernando $\mathrm{A}^{5}$, Sanz $\mathrm{J}^{6}$, Ortega E ${ }^{7}$, Tural $\mathrm{C}^{8}$, Wichmann MA ${ }^{9}$, Zamora FX' and Gónzalez-} García JJ'

${ }^{1}$ HIV Unit, Service of Internal Medicine, Hospital Universitario La Paz, Universidad Autónoma de Madrid, IDIPAZ, Madrid, Spain ${ }^{2}$ Hospital General Universitario Gregorio Marañón, Instituto de Investigación Sanitaria Gregorio Marañón (liSGM), Madrid, Spain

${ }^{3}$ Service of Infectious Diseases, Hospital Clínic/IDIBAPS, University of Barcelona, Barcelona, Spain

${ }^{4}$ Service of Infectious Diseases, Hospital Ramón y Cajal, Madrid, Spain

${ }^{5}$ HIV Unit, Hospital 12 de Octubre and Universidad Europea de Madrid, Madrid, Spain

${ }^{6}$ Service of Internal Medicine, Hospital Universitario Príncipe de Asturias, Alcalá de Henares, Madrid, Spain

${ }^{7}$ Unit of Infectious Diseases, Hospital General Universitario de Valencia, Valencia, Spain

${ }^{8}$ HIV Clinical Unit, Internal Medicine Department and Fundació de la Lluita contra la SIDA, Hospital Universitari Germans Trias i Pujol, Universitat Autònoma de

Barcelona, Barcelona, Spain

${ }^{9}$ Unit of Infectious Diseases, Hospital Donostia, Donostia-San Sebastián, Spain

\begin{abstract}
Aim: We assessed liver stiffness measurement (LSM) for the prediction of mortality and decompensation in HIVinfected patients with compensated liver cirrhosis.

Method: A prospective cohort study of HIV-infected patients with confirmed liver cirrhosis from 9 hospitals in Spain. LSM was undertaken for each patient; clinical events were collected prospectively after the baseline visit, and patients were followed until death or the censoring date. We used univariate/multivariate Cox proportional hazard models to evaluate the utility of LSM for predicting the first hepatic decompensation or overall mortality. The sensitivity (SEN), specificity (SPE), positive predictive value (PPV), negative predictive value (NPV), positive likelihood ratio (LR+) and negative likelihood ratio (LR-) were calculated. The LSM cutoff was selected using ROC curves.
\end{abstract}

Results: We included 102 patients with compensated liver cirrhosis; median [interquartile, (IQR)] follow-up was 36 (21-46) months, median (IQR) CD4+ cell count was 415 cells/ $\mu \mathrm{L}$ (307-624) and 94\% were receiving antiretroviral therapy. The median (IQR) LSM was $17 \mathrm{kPa}$ (11.7-26). Nineteen events were recorded during follow-up. Multivariate analysis showed that time to hepatic decompensation was associated with $\mathrm{CD} 4+<200 \mathrm{cells} / \mu \mathrm{L}(\mathrm{HR}, 26 ; 95 \% \mathrm{Cl}, 1.8-$ $377 ; \mathrm{p}<0.02)$ and LSM $\geq 25 \mathrm{kPa}(\mathrm{HR}, 7.2 ; 95 \% \mathrm{Cl}, 1.1-47 ; \mathrm{p}=0.04)$ and that time to overall mortality was associated with $\mathrm{LSM} \geq 25 \mathrm{kPa}(\mathrm{HR}, 14.3 ; 95 \% \mathrm{Cl}, 1.5-138 ; \mathrm{p}=0.02)$. The predictive values for decompensation (LSM $\geq 25 \mathrm{kPa})$ were as follows: SEN, 67\%; SPE, 78\%; NPV, 96\%; PPV, 23\%; LR+, 3; LR-, 0.4 . The predictive values for overall mortality with this LSM cutoff were as follows: SEN, 86\%; SPE, 79\%; NPV, 99\%; PPV, 23\%; LR+, 4; LR-, 0.2.

Conclusion: Our data suggest that LSM is an accurate method for the prediction of mortality and decompensation in HIV-infected patients with liver cirrhosis.

Keywords: HIV-infected; Liver stiffness; Mortality; Prognosis; Endstage liver disease (ESLD)

\section{Introduction}

End-stage liver disease (ESLD) is a major cause of morbidity and mortality in HIV-infected patients [1,2].The prognosis and management of chronic hepatitis depends on the progression of liver fibrosis and the development of cirrhosis, both of which are accelerated in HIV/HCV co-infected patients [3].

The natural history of cirrhosis is marked by the development of significant portal hypertension, which accurately predicts clinical events and the onset of decompensation [4,5]. Patients with decompensated disease have a much shorter median survival time, particularly HIVinfected patients with liver cirrhosis [6]

Novel non-invasive methodologies such as liver stiffness measurement (LSM) have been developed over the past decade and have replaced liver biopsy for evaluation of liver fibrosis and the progression of liver damage [7,8]. Various studies of ESLD conducted in different clinical settings have demonstrated that LSM values correlate with portal pressure (based on hepatic venous portal gradient) and predict clinical events. Consequently, LSM is beginning to be used to identify patients with cirrhosis who are at risk of disease progression [9-11].
Recent studies have shown that LSM can be used to predict overall mortality, decompensated cirrhosis, hepatocellular carcinoma (HCC), and liver-related mortality in patients with chronic hepatitis $\mathrm{C}$, chronic hepatitis $\mathrm{B}$ and cholestatic liver diseases. Most observational studies have been pooled in a systematic review with meta-analyses by Singh et al. [12], who included data from HIVinfected and non-HIV-infected subjects. Findings suggest that LSM could be incorporated as a prognostic tool into the daily clinical care of patients with liver cirrhosis. Studies on HIV-infected patients are heterogeneous, and only that of Merchante et al. [13] included a large, prospective cohort of $\mathrm{HIV} / \mathrm{HCV}$ co-infected patients with

*Corresponding author: M. Luisa Montes, Hospital Universitario La Paz, Internal Medicine, HIV Unit, Madrid, Madrid 28002, Spain; Tel: +34686624821; E-mail: mmontesr2001@yahoo.es

Received February 28, 2017; Accepted March 08, 2017; Published March 15 2017

Citation: Montes ML, Berenguer J, Miró JM, Quereda C, Hernando A, et al. (2017) Transient Elastography for Predicting Liver-Related Events in Cirrhotic HIV-Infected Patients. J AIDS Clin Res 8: 675. doi: 10.4172/2155-6113.1000675

Copyright: (C) 2017 Montes ML, et al. This is an open-access article distributed under the terms of the Creative Commons Attribution License, which permits unrestricted use, distribution, and reproduction in any medium, provided the original author and source are credited. 
compensated liver cirrhosis managed under a uniform management protocol.

A study that was not included in the meta-analysis by Singh et al. [12] shows that LSM has a higher prognostic value for liver-related events-defined as decompensation or HCC in both HIV/HCV-coinfected patients and HCV-monoinfected patients-than measurement of hepatic venous pressure gradient. This study also showed for the first time that LSM has proven very useful for predicting the development of HCC [14].

The importance of the stage of compensated or decompensated liver disease and the dynamic nature of end-stage liver disease have revolutionized our understanding and care of patients with liver cirrhosis $[4,5,15,16]$.The use of less invasive diagnostic methods and their strong correlation with classic, more invasive, and complicated procedures have made a significant contribution to our knowledge [811,17-19]. These new data are from very different patient populations, whose liver disease had diverse etiologies and characteristics. HIV coinfection is one of the areas where new evidence is similar to that reported for non-HIV-infected persons [9,12-14,18].

Our objectives were to determine the predictive value of LSM for the first hepatic decompensation and overall mortality in HIV-infected patients with liver cirrhosis and to establish a cut-off value to identify those with a high risk of clinical events.

\section{Method}

\section{Study design and patient selection}

Ours was a multicenter prospective cohort study of HIV-infected patients with a diagnosis of liver cirrhosis conducted in 9 hospitals in Spain. Enrollment of the cohort started in June 2004 and finished in June 2005. Patients are still under active follow-up. The population for this study comprised all patients with compensated liver cirrhosis who had undergone LSM. Subjects who were included in the global cohort with decompensated liver cirrhosis criteria or subjects who achieved sustained virological response (SVR) after receiving HCV therapy were excluded from this analysis.

The local ethics committees approved the study, and all patients gave their written informed consent to participate [6].

\section{Patient evaluation and follow-up}

Liver cirrhosis was diagnosed based on liver biopsy findings [20,21], previous diagnosis of liver decompensation, or a Bonacini score $\geq 8$ [22] and was classified as decompensated or compensated based on the presence or absence of a history of hepatic decompensation (ascites, spontaneous bacterial peritonitis, hepatic encephalopathy, upper gastrointestinal bleeding due to portal hypertension or hepatorenal syndrome) $[23,24]$.

Liver stiffness was measured at each center by a single experienced operator using a FibroScan device (EchoSens, Paris, France) with an M probe, as described elsewhere [25,26].

The baseline visit was the one in which the LSM measurement was performed. Clinical events were collected prospectively after the baseline visit and patients were followed until death or the censoring date. Vital status and cause of death were established from the database and clinical records. All patients attended follow-up visits in specialized HIV clinics every 6 months. At each visit, we reviewed clinical events, laboratory data, and Child-Pugh-Turcotte score (CPT). This score ranges from 5 to 15 , with patients classified as follows: score of 5 or 6 ,
CPT class A (well-compensated cirrhosis); score of 7 to 9, CPT class $\mathrm{B}$ (significant functional compromise); and score of 10 to $15, \mathrm{CPT}$ class $\mathrm{C}$ (decompensated cirrhosis). We also recorded the MELD score $\left(3.8^{\star} \log _{e}(\right.$ serum bilirubin $[\mathrm{mg} / \mathrm{dL}])+11.2^{\star} \log _{e}(\mathrm{INR})+9.6^{\star} \log _{\mathrm{e}}($ serum creatinine $[\mathrm{mg} / \mathrm{dL}])+6.4)$, consumption of alcohol and illicit drugs, type of antiretroviral therapy (ART), type of treatment for hepatitis $\mathrm{B}$ and/or C, results of abdominal ultrasound and liver transplant criteria. Clinical care for cirrhosis and associated complications was standard at all the centers.

\section{Study outcome}

We considered first hepatic decompensation as the primary endpoint and death as the secondary endpoint. We excluded hepatocarcinoma as a decompensation event, since it is a biological phenomenon that is not exclusively associated with portal hypertension. Time to the primary endpoint was calculated as the number of months from the baseline visit until the episode of liver decompensation. Time to the secondary endpoint was calculated as months from the baseline visit to death (all causes). Liver-related death was also identified and analyzed.

\section{Statistical analysis}

Qualitative variables are described as frequencies and percentages. Quantitative variables are described as mean with standard deviation (SD) and median with interquartile range (IQR). The normality of the variables was tested using the Kolmogorov-Smirnov-Lilliefors test.

The cumulative incidence and the incidence rate were calculated as measures of frequency of the event for primary and secondary endpoints.

The ability of LSM to predict the first episode of hepatic decompensation or all-cause mortality was assessed using receiver operating characteristic (ROC) curves. We determined the optimal cut-off value of LSM for the first episode of hepatic decompensation or all-cause mortality based on the highest specificity with an acceptable sensitivity $(>60 \%)$. The prognostic value for the first episode of hepatic decompensation or all-cause mortality of FIB- 4 and LSM was compared by calculating the area under the ROC curves (AUROC) using the method proposed by Hanley and McNeil [27].

Survival was analyzed using Kaplan-Meier plots. Survival curves were compared using the log-rank test. We analyzed the impact of prognostic factors on the primary and secondary endpoints, and univariate analysis was performed using Cox regression. Variables with a $\mathrm{p}$ value $\leq 0.1$ in the univariate analysis and clinically relevant variables were included in the multivariate Cox regression model. The continuous variables that could be converted into categorical variables (by defining a clinically relevant cutoff) and fulfilled the eligibility criteria for the analysis were thus included in the multivariate analysis. The variables included in the univariate analysis were age, gender, HCV genotype 2 or 3, HCV therapy, receiving HAART at baseline, CDC stage C, CD4+ cell count $<200$ cells $/ \mu \mathrm{L}$, HIV RNA below the limit of quantification at baseline, Child-Pugh-Turcotte classification stage B or C at baseline, platelet count (quantitative and $<120,000$ cells/mL), MELD score $\geq$ 14 , FIB-4 index (quantitative and $>3.5$ ) and LSM $\geq 25 \mathrm{kPa}$. LSM was included as a categorical variable to maximize its clinical utility. We explored the interaction between LSM and all other covariates included in the multivariate analysis.

Contrast analysis was based on the exact method or normal approximation as required. IBM Statistics 19.0 (IBM Corp., Armonk, NY, USA) was used for the analysis. Statistical significance was set at $\mathrm{p}<0.05$ (2-tailed) for all tests. 


\begin{tabular}{|c|c|}
\hline Baseline characteristics (at LSM visit) & $\mathrm{N}=102$ \\
\hline Median age, years (IQR) & $45(42-48)$ \\
\hline Female, No. (\%) & $25(24.5)$ \\
\hline $\begin{aligned} & \text { Jiagnosis of cirrhosis based on } \\
&- \text { Biopsy No. (\%) } \\
&- \text { Bonacini Score } \geq 8, \text { No. (\%) }\end{aligned}$ & $\begin{array}{l}89(87.3) \\
13(12.7)\end{array}$ \\
\hline $\begin{array}{lll}- & H C V \\
- & H B V \\
- & H C V+H B V \\
- & H C V+\text { prior alcohol abuse }\end{array}$ & $\begin{aligned} 93 & (91.2) \\
4 & (3.9) \\
5 & (4.9) \\
24 & (23.5)\end{aligned}$ \\
\hline $\begin{aligned} & \text { Child-Pugh-Turcotte class, } \text { No. }(\%) \\
&- \text { A5-A6 } \\
&- \text { B-7 } \\
&- \text { Not calculated } \\
&\end{aligned}$ & $\begin{array}{l}56(55) \\
42(42) \\
3(3)\end{array}$ \\
\hline Median (IQR) duration of HIV infection (years) & $18.1(12-20.9)$ \\
\hline $\begin{array}{l}\text { Median (IQR) time since diagnosis of liver cirrhosis, } \\
\text { (years) }\end{array}$ & $5.6(4.3-7.2)$ \\
\hline Transmission route, IVDU, No. (\%) & $88(86.3)$ \\
\hline CDC stage $\mathrm{C}$, No. $(\%)$ & $30(29.7)$ \\
\hline Receiving HAART at baseline, No. (\%) & $96(94.1)$ \\
\hline HIV RNA load <50 copies/mL, No. (\%) & $86(85.1)$ \\
\hline $\begin{aligned} \text { Median (IQR) CD4 cell count, cells/ } \mu \mathrm{L} & \\
- & \text { Baseline } \\
- & \text { Nadir }\end{aligned}$ & $\begin{array}{c}415(307-624) \\
190(73-318)\end{array}$ \\
\hline $\begin{array}{l}\text { Previous therapy against HCV without SVR, No. (\%) } \\
\text { Receiving therapy against HBV (TDF+3TC/FTC), No. (\%) }\end{array}$ & $\begin{array}{l}79(80.6) \\
9(9)\end{array}$ \\
\hline Median (IQR) alanine aminotransferase, IU/L & $59(39-96)$ \\
\hline Median (IQR) aspartate aminotransferase, IU/L & $56(41-94)$ \\
\hline Median (IQR) total bilirubin, $\mathrm{mg} / \mathrm{dL}$ & $0.8(0.5-1.5)$ \\
\hline Median (IQR) platelet count, $\mathrm{mm}^{3}$ & $107(76-169)$ \\
\hline Median (IQR) MELD score & $6(6-9.3)$ \\
\hline Median (IQR) liver stiffness, $\mathrm{kPa}$ & $17(11.7-26)$ \\
\hline Liver stiffness, $\mathrm{kPa}, \mathrm{No} .(\%)$ & $\begin{array}{l}76(74.5) \\
14(13.7) \\
12(11.8)\end{array}$ \\
\hline Median (IQR) FIB-4 index & $2.8(1.8-5.7)$ \\
\hline $\begin{array}{l}\text { FIB-4 index (cirrhosis stage), No. (\%) } \\
* \text { HCY anotype: } 1.61 \% \cdot 2-3.25 \% \cdot 4^{-18 \%>3.25}\end{array}$ & $44(44)$ \\
\hline \multicolumn{2}{|c|}{$\begin{array}{l}\text { LSM: Liver Stiffness Measurement; SD: Standard Deviation; HBV: Hepatitis B Virus; } \\
\text { HCV: Hepatitis C Virus; IQR: Interquartile Range; HIV: Human Immunodeficiency } \\
\text { Virus; IVDU: Intravenous Drug Use; CDC: Centers for Disease Control and } \\
\text { Prevention; HAART: Highly Active Antiretroviral Therapy; TDF: Tenofovir; 3TC: } \\
\text { Lamivudine; FTC: Emtricitabine; MELD: Model for End-Stage Liver Disease; FIB- } \\
\text { 4: Fibrosis } 4 \text { Score }\end{array}$} \\
\hline
\end{tabular}

\section{Results}

\section{Characteristics of the study population}

We included 102 patients who fulfilled the inclusion criteria. The main characteristics of the study population are summarized in Table 1. The main cause of liver cirrhosis was chronic hepatitis $\mathrm{C}$ infection (91\%); $10 \%$ of patients had chronic hepatitis B, and $23 \%$ reported previous alcohol abuse. Eighty-one percent of patients had received therapy against $\mathrm{HCV}$ infection.

With regard to HIV infection, $94 \%$ of patients were receiving ART and $85 \%$ had plasma HIV-RNA<50 copies/mL; median CD4 cell count was 415 cells $/ \mu \mathrm{L}$ at the baseline visit.

The diagnosis of cirrhosis was based on liver biopsy in 89 patients, $55 \%$ of whom were CPT class A; $48 \%$ and $44 \%$ of patients had the highest values in the APRI and FIB-4 scores [28,29], respectively. Thirty-seven patients underwent esophagogastroduodenoscopy, which revealed esophageal varices and/or portal hypertensive gastropathy in $43 \%$. The median value of LSM was $17(11.7-26) \mathrm{kPa}$, and $25 \%$ of patients had an LSM $\geq 25 \mathrm{kPa}$.

\section{Clinical outcomes}

The median follow-up was 36.6 (IQR, 21-46) months, and during this time 9 patients developed hepatic decompensation, 3 developed HCC, 7 died ( 6 from liver-related causes, one from heart failure) and 1 underwent a liver transplant.

The incidence of hepatic decompensation was 3.1 cases (1.15.1) per 100 person years. The most common types of first hepatic decompensation were ascites (6 cases [67\%]) and encephalopathy (3 cases [33\%], 1 of which was associated with portal hypertensive gastrointestinal bleeding).

The AUROC (95\% confidence interval) of LSM was 0.74 (95\% CI, 0.57-0.92; $\mathrm{p}=0.018)$ for the prediction of hepatic decompensation and 0.88 (95\% CI, 0.79-0.97; $\mathrm{p}=0.001)$ for the prediction of all-cause mortality. Different LSM cut-off values for identifying cirrhotic HIVinfected patients with a low risk of developing clinical outcomes were analyzed. The cut-off $\geq 25 \mathrm{kPa}$ was selected based on the highest diagnostic performance, with high sensitivity and specificity. The negative predictive value was over $95 \%$ for hepatic decompensation and mortality (Table 2).

The probability of developing decompensation at 1 year, 2 years, and 3 years was $4 \%, 5 \%$ and $9 \%$, respectively. Patients who had an LSM

\begin{tabular}{|c|c|c|c|c|c|c|}
\hline & \multicolumn{3}{|c|}{ Diagnostic performance for decompensation } & \multicolumn{3}{|c|}{ Diagnostic performance for overall mortality } \\
\hline & LSM>21 Kpa & LSM>25 Kpa & LSM>40 Kpa & LSM>21 Kpa & LSM>25 Kpa & LSM>40 Kpa \\
\hline Sensitivity & $\begin{array}{c}66.7 \% \\
(95 \% \mathrm{Cl}, 30-100)\end{array}$ & $\begin{array}{c}66.7 \% \\
(95 \% \mathrm{Cl}, 30-100)\end{array}$ & $\begin{array}{c}33.3 \% \\
(95 \% \mathrm{Cl}, 0-70)\end{array}$ & $\begin{array}{c}100 \% \\
(95 \% \mathrm{Cl}, 93-100)\end{array}$ & $\begin{array}{c}85.7 \% \\
(95 \% \mathrm{Cl}, 53-100)\end{array}$ & $\begin{array}{c}57 \% \\
(95 \% \mathrm{Cl}, 13-100)\end{array}$ \\
\hline Specificity & $\begin{array}{c}63.4 \% \\
(95 \% \mathrm{Cl}, 53-74)\end{array}$ & $\begin{array}{c}78.5 \% \\
(95 \% \mathrm{Cl}, 70-87)\end{array}$ & $\begin{array}{c}90.3 \% \\
(95 \% \mathrm{Cl}, 84-97)\end{array}$ & $\begin{array}{c}65.2 \% \\
(95 \% \mathrm{Cl}, 55-75)\end{array}$ & $\begin{array}{c}78.9 \% \\
(95 \% \mathrm{Cl}, 70-88)\end{array}$ & $\begin{array}{c}81.6 \% \\
(95 \% \mathrm{Cl}, 85.5-98)\end{array}$ \\
\hline $\begin{array}{l}\text { Positive predictive } \\
\text { value }\end{array}$ & $\begin{array}{c}15 \% \\
(95 \% \mathrm{Cl}, 3-27)\end{array}$ & $\begin{array}{c}23 \% \\
(95 \% \mathrm{Cl}, 5-41)\end{array}$ & $\begin{array}{c}25 \% \\
(95 \% \mathrm{Cl}, 88-54)\end{array}$ & $\begin{array}{c}17.5 \% \\
(95 \% \text { Cl, } 4.5-30.5)\end{array}$ & $\begin{array}{c}23 \% \\
(95 \% \mathrm{Cl}, 5-41)\end{array}$ & $\begin{array}{c}33.3 \% \\
(95 \% \mathrm{Cl}, 2.5-64)\end{array}$ \\
\hline $\begin{array}{l}\text { Negative } \\
\text { predictive value }\end{array}$ & $\begin{array}{c}95 \% \\
(95 \% \mathrm{Cl}, 89-100)\end{array}$ & $\begin{array}{c}96 \% \\
(95 \% \text { Cl, 91-100) }\end{array}$ & $\begin{array}{c}93 \% \\
(95 \% \mathrm{Cl}, 88-99)\end{array}$ & $\begin{array}{c}100 \% \\
(95 \% \text { Cl, 99-100) }\end{array}$ & $\begin{array}{c}98.7 \% \\
(95 \% \mathrm{Cl}, 95-100)\end{array}$ & $\begin{array}{c}97 \% \\
(95 \% \mathrm{Cl}, 92-100)\end{array}$ \\
\hline $\begin{array}{l}\text { Positive likelihood } \\
\text { ratio }\end{array}$ & $\begin{array}{c}1.8 \\
(95 \% \mathrm{Cl}, 1.1-3)\end{array}$ & $\begin{array}{c}3.1 \\
(95 \% \mathrm{Cl}, 1.7-5.7)\end{array}$ & $\begin{array}{c}3.4 \\
(95 \% \text { Cl } 1.1-10.5)\end{array}$ & $\begin{array}{c}2.9 \\
(95 \% \mathrm{Cl}, 2.2-3.8)\end{array}$ & $\begin{array}{c}4.1 \\
(95 \% \mathrm{Cl}, 2.5-6.7)\end{array}$ & $\begin{array}{c}6.8 \\
(95 \% \text { Cl } 2.7-17)\end{array}$ \\
\hline $\begin{array}{l}\text { Negative } \\
\text { likelihood ratio }\end{array}$ & $\begin{array}{c}0.5 \\
(95 \% \mathrm{Cl}, 0.2-1.3)\end{array}$ & $\begin{array}{c}0.4 \\
(95 \% \mathrm{Cl}, 0.2-1.1)\end{array}$ & $\begin{array}{c}0.7 \\
(95 \% \mathrm{Cl} 0.5-1.2)\end{array}$ & 0 & $\begin{array}{c}0.2 \\
(95 \% \mathrm{Cl}, 0.03-1.1)\end{array}$ & $\begin{array}{c}0.5 \\
(95 \% \mathrm{Cl} 0.2-1.1)\end{array}$ \\
\hline
\end{tabular}

Table 2: Liver stiffness diagnostic performance. 
at baseline $\geq 25 \mathrm{kPa}$ were significantly more likely to develop a first hepatic decompensation (Figure 1A).

The factors associated with a first hepatic decompensation were $\mathrm{CD} 4+$ cell count $<200$ cells $/ \mu \mathrm{L}$, receiving antiretroviral therapy at baseline, and LSM. Multivariate Cox regression analysis showed that an LSM $\geq 25 \mathrm{kPa}$ was independently associated with development of a first hepatic decompensation. Confounding variables were included in the regression model and controlled for (Table 3).

The incidence rate for all-cause mortality was $2.3(0.6-4)$ per 100 person-years, and the probability of death at 1 year, 2 years and 3 years was $1 \%, 4 \%$, and $7 \%$. Six patients died from liver-related causes with
ESLD, and 1 patient died from heart failure. Patients with an LSM $\geq 25$ $\mathrm{kPa}$ were significantly more likely to die during follow-up (Figure $1 \mathrm{~B}$ ).

LSM was associated with overall and liver-related death (data not shown), as were $\mathrm{HCV} / \mathrm{HBV}$ therapy, CPT class B or C, CD4+ cell count $<200$ cells/ $\mu \mathrm{L}$, platelet count, and the highest FIB-4 score. Multivariate analysis showed that baseline LSM was independently associated with overall and liver-related mortality. Confounding variables were included in the regression model and controlled for (Table 4).

The multivariate Cox regression analysis did not demonstrate a significant interaction between LSM and any of the other covariates included in the multivariate model, both for the first hepatic decompensation and for overall mortality.

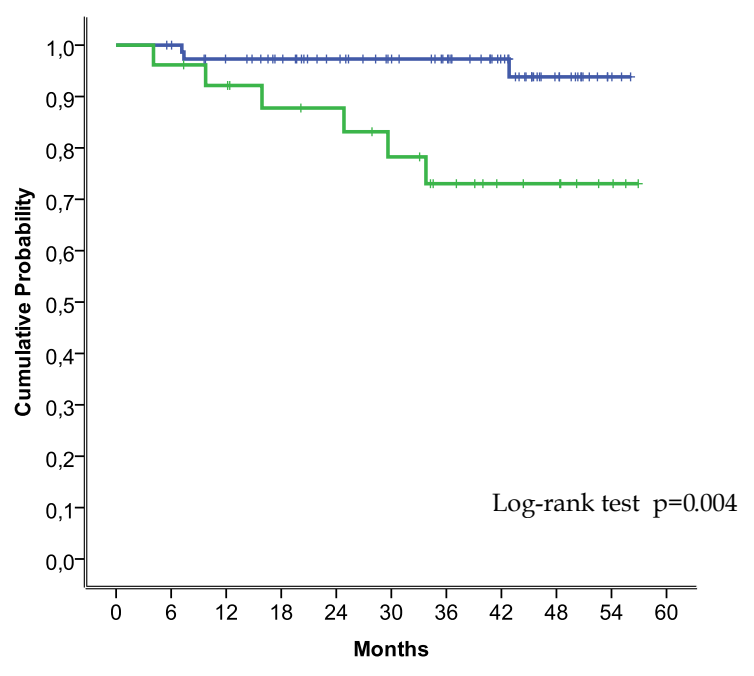

\begin{tabular}{|c|c|c|c|c|c|c|c|c|c|c|c|}
\hline \multicolumn{2}{|c|}{} & \multicolumn{10}{|c|}{ Time (months) } \\
\cline { 3 - 13 } & $\mathbf{0}$ & $\mathbf{6}$ & $\mathbf{1 2}$ & $\mathbf{1 8}$ & $\mathbf{2 4}$ & $\mathbf{3 0}$ & $\mathbf{3 6}$ & $\mathbf{4 2}$ & $\mathbf{4 8}$ & $\mathbf{5 4}$ \\
\hline \multirow{3}{*}{ Number of patients } & FS $<25$ & 76 & 75 & 69 & 63 & 55 & 48 & 42 & 31 & 15 & 3 \\
\cline { 2 - 11 } & $\begin{array}{c}F S \\
25\end{array}$ & 26 & 25 & 23 & 20 & 19 & 16 & 12 & 8 & 7 & 3 \\
\hline
\end{tabular}

Figure 1A: Probability of remaining free from hepatic decompensation according to baseline liver stiffness.

\begin{tabular}{|c|c|c|c|c|}
\hline $\mathrm{N}=102$ & $\begin{array}{l}\text { Univariate analysis } \\
\text { HR }(95 \% \mathrm{Cl})\end{array}$ & $\mathbf{p}$ & $\begin{array}{l}\text { Multivariate analysis } \\
\text { HR }(95 \% \mathrm{Cl})\end{array}$ & $\mathbf{p}$ \\
\hline Age (quantitative) & $1.0(0.9-1.1)$ & 0.73 & & \\
\hline Female & $0.8(0.2-4)$ & 0.81 & & \\
\hline HCV therapy & $1.8(0.2-14.6)$ & 0.57 & $4.7(0.5-44.4)$ & 0.18 \\
\hline Receiving HAART at baseline & $0.2(0-1)$ & 0.05 & $0.13(0.02-0.8)$ & 0.03 \\
\hline HIV RNA BLQ at baseline & $0.5(0.1-2.6)$ & 0.45 & & \\
\hline CD4<200 cells/ $\mu \mathrm{L}$ at baseline & $5.1(1-24)$ & 0.04 & $25.7(1.8-377)$ & 0.02 \\
\hline Child-Pugh-Turcotte stage B at baseline & $0.5(0.1-2.5)$ & 0.6 & $0.2(0.02-2.0)$ & 0.17 \\
\hline CDC stage $\mathrm{C}$ & $1.1(0.2-14)$ & 0.57 & & \\
\hline $\begin{array}{l}\text { Platelets (quantitative) } \\
\text { Platelets }<120,000 \text { cells } / \mathrm{mL}\end{array}$ & $\begin{array}{c}1(1-1.1) \\
2.8(0.6-13.5)\end{array}$ & $\begin{array}{l}0.18 \\
0.20\end{array}$ & & \\
\hline MELD>14 & $0(0-93)$ & 0.69 & - & \\
\hline $\begin{array}{l}\text { FIB-4 (quantitative) } \\
\text { FIB-4>3.5 }\end{array}$ & $\begin{array}{c}1.35(1.1-1.5) \\
4(0.8-20)\end{array}$ & $\begin{array}{l}0.007 \\
0.08\end{array}$ & $1.2(0.2-7.9)$ & 0.85 \\
\hline LSM $\geq 25 \mathrm{kPa}$ & $6(1.5-24.2)$ & 0.01 & $7.2(1.1-46.9)$ & 0.04 \\
\hline
\end{tabular}

HR: Hazard Ratio; Cl: Confidence Interval; HCV: Hepatitis C Virus; HAART: Highly Active Antiretroviral Therapy; HIV: Human Immunodeficiency Virus; BLQ: Below Limit of Quantification; CDC: Centers for Disease Control And Prevention; MELD: Model for End-Stage Liver Disease; FIB-4: Fibrosis 4 Score; LSM: Liver Stiffness Measurement Table 3: Variables associated with hepatic decompensation (ascites, portal hypertensive gastrointestinal bleeding, hepatorenal syndrome, spontaneous bacterial peritonitis, and hepatic encephalopathy). 


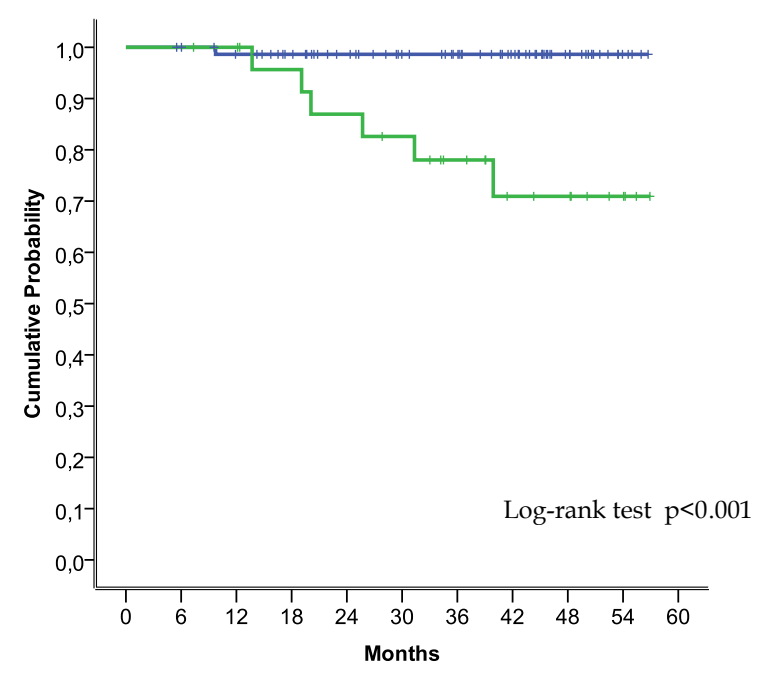

\begin{tabular}{|c|c|c|c|c|c|c|c|c|c|c|c|}
\hline \multicolumn{2}{|c|}{} & \multicolumn{10}{|c|}{ Time (months) } \\
\cline { 3 - 13 } & $\mathbf{0}$ & $\mathbf{6}$ & $\mathbf{1 2}$ & $\mathbf{1 8}$ & $\mathbf{2 4}$ & $\mathbf{3 0}$ & $\mathbf{3 6}$ & $\mathbf{4 2}$ & $\mathbf{4 8}$ & $\mathbf{5 4}$ \\
\hline \multirow{4}{*}{ Number of patients } & $\mathrm{FS}<25$ & 76 & 75 & 71 & 65 & 57 & 49 & 44 & 33 & 17 & 4 \\
\cline { 2 - 13 } & $\begin{array}{c}\mathrm{FS} \geq \\
25\end{array}$ & 26 & 26 & 25 & 22 & 20 & 18 & 14 & 9 & 8 & 4 \\
\hline
\end{tabular}

Figure 1B: Probability of all-cause mortality according to baseline liver stiffness.

\begin{tabular}{|c|c|c|c|c|}
\hline $\mathrm{N}=102$ & $\begin{array}{c}\text { Univariate analysis } \\
\text { HR }(95 \% \mathrm{Cl})\end{array}$ & $\mathbf{p}$ & $\begin{array}{l}\text { Multivariate analysis } \\
\text { HR }(95 \% \mathrm{Cl})\end{array}$ & $\mathbf{p}$ \\
\hline Age (quantitative) & $1.0(0.9-1.2)$ & 0.54 & & \\
\hline Female & $2.2(0.5-9.9)$ & 0.29 & & \\
\hline HCV therapy & $1.2(0.2-10.4)$ & 0.84 & $2.2(0.3-19.5)$ & 0.47 \\
\hline Receiving HAART at baseline & $0.4(0-3.1)$ & 0.36 & & \\
\hline HIV RNA BLQ at baseline & $1(0.1-8.3)$ & 0.99 & & \\
\hline CD4<200 cells $/ \mu \mathrm{L}$ at baseline & $6(1.1-31)$ & 0.03 & $4.4(0.5-34.5)$ & 0.16 \\
\hline Child-Pugh-Turcotte stage $B$ at baseline & $1.5(0.3-6.8)$ & 0.61 & $0.9(0.1-6.1)$ & 0.94 \\
\hline CDC stage $\mathrm{C}$ & $1.3(0.2-9.4)$ & 0.78 & & \\
\hline $\begin{array}{l}\text { Platelets (quantitative) } \\
\text { Platelets }<120,000 \text { cells } / \mathrm{mL}\end{array}$ & $\begin{array}{c}1(0.9-1) \\
50.6 \\
(0.1-24.4)\end{array}$ & $\begin{array}{l}0.04 \\
0.21\end{array}$ & $0.97(0.9-1.0)$ & 0.17 \\
\hline MELD>14 & $0(0-41)$ & 0.70 & & \\
\hline $\begin{array}{l}\text { FIB-4 (quantitative) } \\
\text { FIB-4>3.5 }\end{array}$ & $\begin{array}{l}1.3(1.1-1.6) \\
7.2(0.9-60)\end{array}$ & $\begin{array}{c}0.004 \\
0.07\end{array}$ & $0.4(0.02-8.1)$ & 0.51 \\
\hline LSM $\geq 25 \mathrm{kPa}$ & $18(2.1-147)$ & 0.008 & $14.3(1.5-137.8)$ & 0.02 \\
\hline
\end{tabular}

HR: Hazard Ratio; Cl: Confidence Interval; HCV: Hepatitis C Virus; HAART: Highly Active Antiretroviral Therapy; HIV: Human Immunodeficiency Virus; BLQ: Below Limit of Quantification; CDC: Centers for Disease Control And Prevention; MELD: Model for End-Stage Liver Disease; FIB-4: Fibrosis 4 Score; LSM: Liver Stiffness Measurement Table 4: Variables associated with overall mortality.

\section{Discussion}

Our study showed that LSM has high prognostic value, enabling us to classify with a fair degree of accuracy patients who will develop complications of cirrhosis in the coming 3 years and patients who are more at risk of all-cause mortality. The variables $L S M \geq 25 \mathrm{kPa}$ and $\mathrm{CD} 4+<200$ cells $/ \mu \mathrm{L}$ were predictive both of liver decompensation and of death. Our sample was homogeneous in that it comprised HIVinfected patients with compensated liver cirrhosis who were followed up under the same protocol for a median of 36 months. All the patients had HIV infection that was well controlled with ART and most patients had a good immunological status.
Interaction between the variables included in the analysis was ruled out; the significant value of LSM was maintained in the multivariate analysis and proved to be independent of other relevant factors of hepatic morbidity and mortality (e.g. CPT stage, Model for End-Stage Liver Disease [MELD] score, and FIB-4 score) and other confounding factors. Unexpectedly, CPT class and MELD score were not prognostic factors. We believe the CPT class and the absence of an association with the variables analyzed are consequences of the low number of events and the characteristics of the study patients, that is, patients with CPT class B (mainly B7) and scores based on laboratory values and not on clinical factors are barely differentiated from class A6 patients. 
We did not find a significant association for exposure to HCV therapy. As we excluded patients with a sustained virological response, partial response to HCV therapy has a minimal impact on liver-related events. Larger samples and longer follow up studies have demonstrated this association [30-32].

We did not present an independent analysis for liver-related mortality because all the deaths recorded (except 1) were liver-related, and our results were completely consistent between both mortality analyses.

Our results are also consistent with data from other studies on HIV/HIV co-infected patients, although they differ in that a greater strength of association was found between the main variables analyzed individually. We believe this difference is due to the characteristics of the study patients [12-14]. The patients analyzed had liver cirrhosis caused by long-standing viral hepatitis. Most were receiving highly active antiretroviral therapy, more than $90 \%$ had an undetectable viral load and more than $80 \%$ had already received treatment for $\mathrm{HCV}$ infection. They also had advanced liver disease, $40 \%$ were CPT class B and a similar percentage had high scores in the serological index FIB-4.

Despite its small sample size, our study has features that add particular interest with respect to other published studies [12-14]. First, patients with a sustained virological response to hepatitis $C$ were excluded. Second, the main variable analyzed was a non-composite endpoint. And third, first liver decompensation was defined as the onset of ascites, digestive bleeding resulting from portal hypertension, hepatic encephalopathy, hepatorenal syndrome, or spontaneous bacterial peritonitis, but not HCC. Furthermore, the main variable does not include esophageal varices, since the accepted definition of decompensation of liver cirrhosis is bleeding caused by portal hypertension, but not the presence of uncomplicated varices [23,24]. Lastly, our study establishes a significant and independent cut-off LSM value that enables us to discriminate between patients with a very low risk of developing clinical complications (all types) and, therefore, to safely exclude them from more intensive or aggressive approaches.

\section{Prior studies of LSM for predicting liver events}

The first published study on the value of LSM for predicting liver events in HIV-infected patients was by Merchante et al. [13], who included 239 subjects diagnosed with cirrhosis using LSM; more than half had a value $>25 \mathrm{kPa}$. The clinical event rates reported are higher than those of our study, since the patients included had HCC and a significant percentage $(39 \%)$ received treatment for HCV infection during follow-up, which could have caused further liver decompensation. As for global mortality, our results are very similar. In the study by Merchante et al. [13], the cut-off for patients with the highest probability of developing more clinical events was set at $40 \mathrm{kPa}$. However, it is noteworthy that in patients with an $\mathrm{LSM}<40 \mathrm{kPa}$, the probability of decompensation or HCC was 0.2 at 3 years. Although this value is significantly lower than that of patients with an LSM of $>40$ $\mathrm{kPa}$ and a 3 year probability of 0.35 , we believe that it is still excessively high. The situation is similar for prediction of liver-related death or of transplant. We believe that an LSM cut-off of $25 \mathrm{kPa}$ is better correlated with high values for significant portal hypertension, which is a more appropriate marker of subsequent development of clinical events. CPT class in this cohort remained significant. MELD score was not significantly associated with liver events or liver-related mortality, and its predictive value remained open to debate in HIV/HCV co-infected patients, since the analysis presented is from the first 2 years.

The second published study on co-infected patients [18] differs significantly from our study with regard to the patients included, in that only one-third of the patients had LSM values corresponding to F3-F4 (even though a significant association was found between LSM values and emergence of clinical events); therefore, the event rates were very low despite a very long follow-up and inclusion of more than 500 patients. Nevertheless, it is difficult to draw comparisons, since only crude rates without confidence intervals are presented and the $10 \%$ decompensation frequency reported includes 28 cases (i.e., more than half) with a diagnosis of non-bleeding esophageal varices, which is not usually included in the definition of cirrhosis with decompensation $[23,24]$. Mortality was significantly lower than that of our study and that reported by Merchante et al. [13], since patients had less advanced liver disease. For the same reason, most deaths were not liver-related. On the contrary, this study did reveal an association between sustained virological response and lower mortality owing to the large sample size and a mean follow-up that was much longer than in the study by Merchante et al. and the present study.

The third major publication on the prognostic value of LSM in liver cirrhosis in co-infected patients is the systematic review and metaanalysis by Singh et al. [12], which includes all studies on the ability of LSM to predict liver events and death irrespective of the etiology. Of the 17 studies included, 5 were in HIV/HCV co-infected patients, although only the studies by Fernández-Montero et al. [18] and Merchante et al. [13] were designed to predict liver events. Nevertheless, the results of the meta-analysis are robust and show that LSM is a non-invasive test with a high capacity to predict HCC and death in ESLD of various causes. As for the significant result in prediction of HCC, we believe that the high percentage of cases of chronic hepatitis $\mathrm{B}$ and liver disease during the post-transplant period can justify findings that have not been replicated in individual studies on HIV-infected patients.

Our results are largely consistent with those of Pérez-Latorre et al. [14], which also confirm an excellent correlation between the value of the hepatic venous pressure gradient and LSM. The authors report 2 cut-offs for predicting absence of liver events $(<25 \mathrm{kPa})$ and presence of liver events ( $>40 \mathrm{kPa}$ ) (first to occur of decompensation or HCC). Our cut-off of $25 \mathrm{kPa}$, which was chosen as the optimal value for predicting the absence of decompensation, is similar to that reported by PérezLatorre et al. [14] and our cut-off of $40 \mathrm{kPa}$ for predicting the presence of events is the same as that reported by Merchante et al. [13]. The determination of both points may well be complementary and enable better prediction of liver events in HIV/HCV co-infected patients.

\section{Limitations}

Our study is subject to a series of limitations. The sample size was small, and the number of clinical events relatively low. This could have prevented identification of another, weaker predictive factor or led to later identification of the predictive factor. However, the population studied was homogeneous, very stable, and closely monitored, with less than $5 \%$ of losses. Control of HIV infection was excellent: more than $90 \%$ of patients had an undetectable viral load, which is a crucial factor when determining survival and progression of liver disease, as shown in various studies $[6,13,30-32]$. Despite these limitations, the study was able to show that an LSM cut-off $\geq 25 \mathrm{kPa}$ can predict clinical events and overall and liver-related mortality and that this information can be applied to better identify HIV-infected patients with compensated liver cirrhosis who are at higher risk.

\section{Conclusion}

In conclusion, baseline LSM is an independent predictor of hepatic decompensation and global liver-related mortality in HIV-infected 
patients with compensated cirrhosis caused by viral hepatitis who is taking antiretroviral therapy. Patients with these characteristics (i.e., most of those with cirrhosis currently attended in HIV units) and an LSM $>25 \mathrm{kPa}$ should be followed more closely. Every effort should be made to optimize management of ESLD. We believe there is a need for new prospective studies that analyze changes in LSM and how these changes can help to better identify patients at greater risk.

\section{Core Tip}

We analyzed a prospective national cohort to evaluate the utility of liver stiffness measurement for prediction of clinical events in HIV-infected persons with liver cirrhosis. Patients who had a liver stiffness measurement $\geq 25 \mathrm{kPa}$ were significantly more likely to develop a first hepatic decompensation or die during follow-up. These high-risk patients should be followed more closely, and every effort should be made to optimize management of end-stage liver-disease and to refer them to specific liver transplant units when other treatment options are not possible.

\section{Acknowledgement}

GESIDA 37/03.FIPSE 364665/03-NEAT IG5 Investigators Study Group Investigators: MaLuisa Montes Ramírez, José Ramón Arribas, Francisco Xavier Zamora Vargas, Juan Miguel Castro, Mario Mayoral, Juan J González-García, Francisco Arnalich (Hospital Universitario La Paz, Madrid); María Asunción Hernando, Federico Pulido, Rafael Rubio, María Lagarde, Mariano Matarranz (Hospital Universitario 12 de Octubre, Madrid); Juan Berenguer Berenguer Margarita Ramírez, Isabel Gutiérrez, Pilar Miralles, Juan carlos López, Teresa Aldámiz, Ana Carrero, Cristina Díez, Francisco Tejerina (Hospital General Universitario Gregorio Marañón, Madrid); Carmen Quereda, Ana Moreno, Ma Jesús Pérez-Elías, Antonia Sanfrutos, José Luis Casado, Fernando Dronda, Santiago Moreno (Hospital Universitario Ramón y Cajal, Madrid); José Sanz-Moreno, Julio de Miguel Prieto, Alberto Arranz Caso, Esperanza Casas García (Hospital Universitario Príncipe de Asturias, Madrid). Enrique Ortega González, Purificación Rubio Cuevas, Laura Ortiz Ramírez de Arellano (Hospital General Universitario de Valencia), Cristina Tural Llacher, Antoni Jou Pastor (Hospital Germans Trias Pujol, Badalona); José M Miró, Christian Manzardo, Fernando Agüero, Montserrat Laguno, Alejandro Forner, Josep Mallolas, Antonio Rimola (Hospital ClínicIDIBAPS, University of Barcelona, Barcelona, Spain); Miguel Ángel Von Wichmann de Miguel, José Antonio Iribarren, Francisco Rodriguez-Arrondo (Unit of Infectious Diseases, Hospital Universtario Donostia, Donostia-San Sebastián, Spain); Hermina Esteban, Lucía Serrano (Fundación SEIMC-GESIDA, Madrid).

\section{Author Contributions}

Montes ML, Berenguer J, and Miró JM provided scientific input with respect to the study design and protocol. Montes ML created the database and provided scientific input for the statistical analysis, which was performed by Lucia Serrano (author in Acknowledgements). Castro JM, Ramírez M, and Gutiérrez I (authors in Acknowledgements) performed the transient elastography evaluations. All authors assessed clinical data from the study. Montes ML wrote the first draft of the manuscript. O'Boyle T provided writing assistance during the preparation of the manuscript. All authors assessed, reviewed, and edited the manuscript and approved the final version for publication.

\section{Informed Consent Statement}

All study participants, or their legal guardians, provided written consent prior to enrolment.

\section{Financial Support}

This study was supported by the following grants: FIPSE $36465 / 03$, FIPSE 36680/07.-NEAT IG5 Study Group (NEAT is a project funded by the European Union under the 6th Framework programme, contract number LSHPCT-2006-037570) and Red de Investigación en SIDA (AIDS Research Network) (RIS) (ref. RD07/0006/2007). Berenguer $\mathrm{J}$ is an investigator from the Programa de Intensificación de la Actividad Investigadora en el Sistema Nacional de Salud (I3SNS). Refs INT10/009 and INT12/154.

\section{References}

1. Tuma P, Jarrin I, Del Amo J, Vispo E, Medrano J, et al. (2010) Survival of HIVinfected patients with compensated liver cirrhosis. AIDS 24: 745-753.

2. Kim AY, Onofrey S, Church DR (2013) An epidemiologic update on hepatitis C infection in persons living with or at risk of HIV infection. J Infect Dis 207 Suppl 1: S1-S6.
3. Macías J, Berenguer J, Japón MA, Girón JA, Rivero A, et al. (2009) Fast fibrosis progression between repeated liver biopsies in patients co-infected with human immunodeficiency virus/hepatitis C virus. Hepatology 50: 1056-1063.

4. Ripoll C, Groszmann R, Garcia-Tsao G, Grace N, Burrouhgs A, et al. (2007) Hepatic venous pressure gradient predicts clinical decompensation in patients with compensated cirrhosis. Gastroenterology 133: 481-488.

5. Garcia-Tsao G, Friedman S, Iredale J, Pinzani M (2010) Now there are many (stages) where before there was one: In search of a pathophysiological classification of cirrhosis. Hepatology 51: 1445-1449.

6. López-Diéguez M, Montes ML, Pascual-Pareja JF, Quereda C, Von Wichmann MA, et al. (2011) The natural history of liver cirrhosis in HIV-hepatitis $C$ virus co-infected patients. AIDS 25: 899-904.

7. Sánchez-Conde M, Montes-Ramírez ML, Miralles P, Alvarez JM, Bellón JM et al. (2010) Comparison of transient elastography and liver biopsy for the assessment of liver fibrosis in HIV/hepatitis $\mathrm{C}$ virus co-infected patients and correlation with non-invasive serum markers. J Viral Hepat 17: 280-286.

8. Castera L, Vergniol J, Foucher J, Le Bail B, Chanteloup E, et al. (2005) Prospective comparison of transient elastography, fibrotest, APRI, and liver biopsy for the assessment of fibrosis in chronic hepatitis C. Gastroenterology 128: 343-350.

9. Sanchez-Conde M, Miralles P, Bellon JM, Rincón D, Ramírez M, et al. (2011) Use of transient elastography (FibroScan(R)) for the non-invasive assessment of portal hypertension in HIV/HCV co-infected patients. J Viral Hepat 18: 685691.

10. Robic MA, Procopet B, Metivier S, Perón JM, Selves J, et al. (2011) Liver stiffness accurately predicts portal hypertension related complications in patients with chronic liver disease: A prospective study. J Hepatol 55: 10171024.

11. Castera L, Pinzani M, Bosch J (2012) Non invasive evaluation of portal hypertension using transient elastography. J Hepatol 56: 696-703.

12. Singh S, Fujii LL, Murad MH, Wang Z, Asrani SK, et al. (2013) Liver stiffness is associated with risk of decompensation, liver cancer and death in patients with chronic liver diseases: A systematic review and meta-analysis. Clin Gastroenterol Hepatol 11: 1573-1584.

13. Merchante N, Rivero-Juarez A, Tellez F, Merino D, José Ríos-Villegas M, et al (2012) Liver stiffness predicts 385 clinical outcome in human immunodeficiency virus/hepatitis C virus-co-infected patients with compensated liver cirrhosis. Hepatology 56: 228-238.

14. Pérez-Latorre $L$, Sánchez-Conde $M$, Rincón $D$, Miralles $P$, Aldámiz-Echevarría $T$, et al. (2014) Prediction of Liver complications in patients with hepatitis $C$ virus-related cirrhosis with and without HIV co-infection: Comparison of hepatic venous pressure gradient and transient elastography. Clin Infect Dis 58: 713718.

15. Garcia-Tsao G, Bosch J, Groszmann RJ (2008) Portal hypertension and variceal bleeding-unresolved issues: Summary of an American Association for the Study of Liver Diseases and European Association for the Study of the Liver single-topic conference. Hepatology 47: 1764-1772

16. Zipprich A, Garcia-Tsao G, Rogowski S, Fleig WE, Seufferlein T, et al. (2012) Prognostic indicators of survival in patients with compensated and decompensated cirrhosis. Liver Int 32: 1407-1414.

17. Rincon D, Lo lacono O, Tejedor M, Hernando A, Ripoll C, et al. (2013) Prognostic value of hepatic venous pressure gradient in patients with compensated chronic hepatitis C-related cirrhosis. Scand J Gastroenterol 48: 487-495.

18. Fernandez-Montero JV, Barreiro P, Vispo E, Labarga P, Sánchez-Parra C, et al. (2013) Liver stiffness predicts liver-related complications and mortality in HIV patients with chronic hepatitis C on antiretroviral therapy. AIDS 27: 1129-1134.

19. Colecchia A, Montrone L, Scaioli E, Bacchi-Reggiani ML, Colli A, et al (2012) Measurement of spleen stiffness to evaluate portal hypertension and the presence of esophageal varices in patients with HCV-related cirrhosis. Gastroenterology 143: 646-654.

20. Knodell RG, Ishak KG, Black WC, Chen TS, Craig R, et al. (1981) Formulation and application of a numerical scoring system for assessing histological activity in asymptomatic chronic active hepatitis. Hepatology 1: 431-435.

21. Bedossa P, Poynard T (1996) An algorithm for the grading of activity in chronic hepatitis C. The METAVIR Cooperative Study Group. Hepatology 24: 289-293. 
Citation: Montes ML, Berenguer J, Miró JM, Quereda C, Hernando A, et al. (2017) Transient Elastography for Predicting Liver-Related Events in Cirrhotic HIV-Infected Patients. J AIDS Clin Res 8: 675. doi: 10.4172/2155-6113.1000675

22. Bonacini M1, Hadi G, Govindarajan S, Lindsay KL (1997) Utility of a discriminant score for diagnosing advanced fibrosis or cirrhosis in patients with chronic hepatitis C virus infection. Am J Gastroenterol 92: 1302-1304.

23. European Association for Study of Liver (2015) EASL recommendations on treatment of hepatitis C 2015. J Hepatol 63: 199-236.

24. Ghany MG, Strader DB, Thomas DL, Seeff LB, American Association for the Study of Liver Diseases (2009) Diagnosis, management and treatment of hepatitis C: An update. Hepatology 49: 1335-1374

25. Sandrin L, Fourquet B, Hasquenoph JM, Yon S, Fournier C, et al. (2003) Transient elastography: A new non-invasive method for assessment of hepatic fibrosis. Ultrasound Med Biol 29: 1705-1713.

26. Castera L, Forns X, Alberti A (2008) Non-invasive evaluation of liver fibrosis using transient elastography. J Hepatol 48: 835-847.

27. Hanley JA, McNeil BJ (1983) A method of comparing the areas under receiver operating characteristic curves derived from the same cases. Radiology 148 : 839-843.
28. Sterling RK, Lissen E, Clumeck N, Sola R, Correa MC, et al. (2006) Development of a simple noninvasive index to predict significant fibrosis in patients with HIV/ HCV co-infection. Hepatology 43: 1317-1325.

29. Wai CT, Greenson JK, Fontana RJ, Kalbfleisch JD, Marrero JA, et al. (2003) A simple non-invasive index can predict both significant fibrosis and cirrhosis in patients with chronic hepatitis C. Hepatology 38: 518-526.

30. Berenguer J, Alvarez-Pellicer J, Martín P, López-Aldeguer J, Von-Wichmann $M A$, et al. (2009) Sustained virological response to interferon plus ribavirin reduces liver-related complications and mortality in patients co-infected with HIV and hepatitis C virus. Hepatology 50: 407-413.

31. Berenguer J, Rodríguez E, Miralles P, Von Wichmann MA, López-Aldeguer J et al. (2012) Sustained virological response to interferon plus ribavirin reduces non-liver-related mortality in patients co-infected with HIV and hepatitis $\mathrm{C}$ virus. Clin Infect Dis 55: 728-736.

32. Merchante N, Giro'n-Gonza'lez JA, Gonza'lez-Serrano M, Torre-Cisneros J Garci'a-Garci'a JA, et al. (2006) Survival and prognostic factors of HIV-infected patients with HCV-related end-stage liver disease. AIDS 20: 49-57. 